\title{
HEMATO-BIOCHEMICAL ANALYSES OF LACTATING CROSS-BRED JERSEY CATTLE AT KASKI DISTRICT, NEPAL
}

\author{
B. Regmi ${ }^{1 *}$, K.R. Pande ${ }^{2}$ \\ ${ }^{1}$ Institute of Agriculture and Animal Science, Tribhuvan University, Nepal \\ ${ }^{2}$ Senior Veterinary Officer, Regional Veterinary Laboratory, Ramghat, Pokhara, Nepal \\ *regmibharat2008@gmail.com
}

\begin{abstract}
Hemato-biochemical profiles have been used widely to identify the health problems associated with productive and reproductive disorders. The objective of this study was to set up a baseline hematological and serum biochemical values. The study was carried out in 50 lactating cross bred Jersey cattle of Kaski district ranging in age from 3-7 years. Non-pregnant, lactating, apparently healthy and stall-fed cattle were selected for sampling and these animals were regularly dewormed and vaccinated against common diseases. All the hematological parameters were determined on the same day of collection using auto analyzer. The samples were also tested for blood protozoans (Anaplasma, Babesia, Theleria and Trypanosoma), using thin and thick smears. The serum samples were collected in a sterile vial for serum biochemical analysis and preserved at $-20^{\circ} \mathrm{C}$ until used for the assays. All the hematological parameters were within the normal range. However, $2 \%$ of the total animals tested appeared Theleria positive. Eosinophil and basophils were within the normal range suggesting that the deworming was effective and there was no allergic reaction. Mineral profile particularly glucose $(11.75 \pm 0.87)$ was found significantly $(\mathrm{P}<0.05)$ low. This suggests that cross Jersey cattle were prone to hypoglycemia related metabolic disorders and corrective measures should be employed for better production. The values obtained in this study within the range can be used cautiously as reference value at lactating stage of cross-bred Jersey cattle. Further detail study is needed to exacting the standard reference value for this breed of cattle.
\end{abstract}

Keywords: Hemato-biochemical profile; Cross-bred Jersey cattle; Blood biochemical analysis

\section{INTRODUCTION}

Hematological and blood serum biochemical profile testing is a pre-symptomatic diagnostic tool to assess the dairy herd's nutritional status and other productive and reproductive disorders (Pathan et al., 2011). The peri-parturient period of three weeks in dairy cattle is associated with multiple changes including hormonal changes, moving from non-lactating to lactating state as well as a major drop in feed intake and switching of the diet from a roughage-based diet (i.e. hay and grass) into a diet rich in rapidly fermentable carbohydrates (i.e. high-grain diets) (Burim, 2006). One in two dairy cows in a herd is affected by one or multiple metabolic disorders. The profile may vary according to factors such as origin, climate, management practices, geographical distribution, season and stage of animals (Lee et al., 1978; Cozzi et al., 2011; Pal \& Acharya, 2013; Mahima et al., 2013). So, it is important to determine the hematological and blood biochemical profile for the clinical interpretation of laboratory findings especially in the post parturient stage in which the cattle are more likely to suffer from metabolic disorders due to the draining of minerals like calcium and phosphorus in the milk which may lead to hypocalcaemia, hypomagnesaemia and milk fever (Pal \& Acharya, 2013). The metabolic diseases are highly associated with each other like cows affected by milk fever are more prone to mastitis, retained placenta, metritis, left abomasal displacement (LDA), dystocia, udder edema and ketosis (Burim, 2006). Pal and Acharya (2013) have documented the hematological and serum biochemical parameters in post -parturient stage of Holstein cross cattle at the central part of Nepal (Pal \& Acharya, 2013) but no report has been documented in the Jersey cross-bred cattle at the western part of Nepal although the Jersey cross-bred are the major cattle breed raised in Nepal. 
As a result of using unspecific reference values, dairy practitioners, entrepreneurs and farmers have been experiencing higher rates of misdiagnosis, mistreatment, and mismanagement of metabolic disorders in the herd (Pal \& Bhatta, 2013). In this study, we aimed to find out the normal hematobiochemical profile of apparently healthy commercial Jersey cross-bred cattle at the lactating stage. This study will also helpful to uncover the subclinical metabolic diseases.

\section{MATERIALS AND METHODS}

A questionnaire survey was conducted in the commercial cattle farm of Pokhara-Lekhnath metropolitan city of Kaski district. The record of identification, breed, age, lactation, parity, vaccination, deworming, medication, feeds, feeding methods, reproductive or any other disorders were noted. Pregnancy was confirmed through history and rectal palpation. This cross sectional study was conducted from November, 2015- February, 2016. Clinical examination was also performed to select the healthy animals. The blood Sample from 50 apparently healthy Jersey cross cattle having same feeding method, vaccinated against common diseases (Foot and Mouth Disease, Hemorrhagic Septicemia and Black Quarter) and regularly dewormed in the period of 6 months, ranging from 3 to 7 years of age were taken. The blood sample was collected from jugular vein using vacutainer tubes. Each sample was tested for blood parasites (Babesia, Anaplasma, Trypanosoma and Theleria) by making thin and thick smear and stained with Giemsa's stain according to the method described by Benjamin, (1986). The sample found positive for blood protozoans were not used for determining the reference range. Hematological parameters were determined on the same day of collection using automated analyzer and the serum samples were collected in a sterile vial for biochemical analysis and preserved at $-20^{\circ} \mathrm{C}$ until further analysis. Calcium $(\mathrm{Ca})$, phosphorus $(\mathrm{P})$, magnesium, total protein (TP), glucose, albumin (A), globulin (G) was estimated using Spectrophotometer. Ca: $\mathrm{P}$ and $\mathrm{A}: \mathrm{G}$ was also calculated. Globulin concentration is determined by subtracting albumin from total protein. The statistical data were interpreted by descriptive statistical tool (computer software Microsoft Excel 2010, beta) and expressed at 95\% level of confidence as mean, standard error and standard deviation. Finally, the data were compared with the standard value (Kahn, et al., 2010) using $\mathrm{t}$ - test and significance was set at 5 percent $(\mathrm{p}<0.05)$.

\section{RESULTS}

Table 1: Estimated values for hematologic indices

\begin{tabular}{llllll}
\hline Variables & Units & $\begin{array}{l}\text { Mean Standard } \\
\text { Error }\end{array}$ & $\begin{array}{l}\text { Standard } \\
\text { Deviation }\end{array}$ & $\begin{array}{l}\text { Confidence } \\
\text { Level (95\%) }\end{array}$ & $\begin{array}{l}\text { RR (Kahn, et al., } \\
2010)\end{array}$ \\
\hline WBC & $\mathrm{X} 10^{3} / \mathrm{mm}^{3}$ & $5.63 \pm 0.29$ & 2.04 & 0.59 & $4-12$ \\
$\mathrm{RBC}$ & $\mathrm{X} 10^{6} / \mathrm{mm}^{3}$ & $5.48 \pm 0.09$ & 0.67 & 0.19 & $5-10$ \\
Platelets & $\mathrm{X} 10^{3} / \mathrm{mm}^{2}$ & $277.45 \pm 26.45$ & 185.18 & 53.19 & $100-800$ \\
$\mathrm{Hb}$ & $\mathrm{gm} / \mathrm{dl}$ & $9.48 \pm 0.21$ & 1.47 & 0.42 & $8-15$ \\
$\mathrm{PCV}$ & $\%$ & $31.18 \pm 1.19$ & 8.32 & 2.39 & $24-46$ \\
Neutrophils & $\%$ & $10.88 \pm 0.96$ & 6.7 & 1.92 & $15-45$ \\
Lymphocytes & $\%$ & $77.78 \pm 1.85$ & 12.93 & 3.71 & $45-75$ \\
Eosinophils & $\%$ & $5.27 \pm 0.59$ & 4.19 & 1.2 & $2-20$ \\
Monocytes & $\%$ & $4.22 \pm 0.49$ & 3.04 & 0.87 & $2-7$ \\
Basophils & $\%$ & $0.04 \pm 0.03$ & 0.19 & 0.06 & $0-2$ \\
MCV & $\mathrm{Fl}$ & $54.18 \pm 1.75$ & 12.26 & 3.52 & $40-80$ \\
$\mathrm{MCH}$ & $\mathrm{Pg}$ & $16.24 \pm 0.29$ & 2.03 & 0.58 & $11-17$ \\
$\mathrm{MCHC}$ & $\%$ & $30.25 \pm 0.36$ & 2.52 & 0.72 & $30-36$ \\
\hline
\end{tabular}


Out of 50 samples tested for blood protozoans one was found positive for Theleria ( $2 \%$ of the total examined apparently healthy cattle) and rest samples were used for the determination of hematological and serum biochemical reference values. There were altogether 13 hematological variables analyzed and all the values were found within the normal range (Table 1). Similarly, out of 9 serum biochemical parameters evaluated, glucose level was recorded significantly $(p<0.05)$ lower than reference value (Table 2).

Table 2: Estimated values for biochemical parameters in serum

\begin{tabular}{|c|c|c|c|c|c|}
\hline Variables & Units & $\begin{array}{l}\text { Mean Standard } \\
\text { Error }\end{array}$ & $\begin{array}{l}\text { Standard } \\
\text { Deviation }\end{array}$ & $\begin{array}{l}\text { Confidence } \\
\text { Level }(95 \%)\end{array}$ & $\begin{array}{l}\text { RR (Kahn et al., } \\
\text { 2010) }\end{array}$ \\
\hline Glucose & $\mathrm{gm} / \mathrm{dl}$ & $11.75 \pm 0.87^{*}$ & 6.11 & 1.75 & $42.1-74.5$ \\
\hline $\begin{array}{l}\text { Total } \\
\text { Protein }\end{array}$ & $\mathrm{gm} / \mathrm{dl}$ & $6.74 \pm 0.14$ & 0.97 & 0.28 & $6.2-8.2$ \\
\hline Calcium & $\mathrm{mg} / \mathrm{dl}$ & $6.07 \pm 0.17$ & 1.18 & 0.34 & 8.4- 11 \\
\hline Phosphorus & $\mathrm{mg} / \mathrm{dl}$ & $7.12 \pm 0.19$ & 1.39 & 0.39 & $4.3-7.8$ \\
\hline Magnesium & $\mathrm{mg} / \mathrm{dl}$ & $2.15 \pm 0.05$ & 0.37 & 0.11 & $1.7-3$ \\
\hline Albumin & $\mathrm{gm} / \mathrm{dl}$ & $2.75 \pm 0.05$ & 0.37 & 0.11 & 2.8- 3.9 \\
\hline Globulin & $\mathrm{gm} / \mathrm{dl}$ & $3.89 \pm 0.14$ & 0.98 & 0.28 & $2.9-4.9$ \\
\hline A: $G$ & - & $0.86 \pm 0.11$ & 0.82 & 0.24 & $0.79-0.97$ \\
\hline Ca: P & - & $0.89 \pm 0.04$ & 0.3 & 0.09 & $1.41-1.95$ \\
\hline
\end{tabular}

\section{DISCUSSION}

All the hematological parameters were found within the range. Increase in eosinophils due to stress or some internal and external parasitic infestations observed previously was not found in this study (Pal \& Acharya, 2013). This means that the cows are adapted to this climatic conditions and deworming is effective which was confirmed finally through fecal examination. Other typical changes of acute stress in cows like neutropenia or lymphopenia (Jain \& Lasmanis, 1978) were also not observed. The decrease in basophils is not observed suggesting for no obvious parasitic infection and allergic reactions. The result is in agreement with Pal \& Acharya (2013) for Holstein Friesian cross-bred cattle in central part of Nepal except eosinophilia, monocytosis and basopenia which may be due to different sampling method, season, climate and management system. The results obtained in the present study are in agreement with the reports of different other researches (Bozdogan \& Baysal, 2003; Pal \& Bhatta, 2013).

There was a marked decrease in calcium level $6.07 \pm 0.17 \mathrm{mg} / \mathrm{dl}$ than the normal values recorded for healthy cattle $8.19 \pm 0.83 \mathrm{mg} / \mathrm{dl}$. The drop in calcium levels may be the result of the impaired absorption of food metabolites from the gastro-intestinal precursor, excessive losses through urine and more importantly overload of supplying mineral component into milk (Hagawane, Shinde \& Rajguru, 2009). Nehra (2016) revealed a significant decrease in calcium during early lactation. Drop in calcium intake of 100-125 gm/day results in a higher incidence of milk fever than lesser amounts (Radostits \& Done, 2007). Low calcium and high phosphorus diets increase mobilizable calcium to $60 \%$ of total body calcium through the activation of parathyroid hormone (PTH) as compared 
to $37 \%$ for high Ca low $\mathrm{P}$ diets (Lee et al., 1978). The incidence of milk fever can be reduced by prepartum feeding of diets low in Ca but more than adequate in $\mathrm{P}$ (McCullough, 1969).

There was a significant decrease in serum glucose level $11.75 \pm 0.87 \mathrm{gm} / \mathrm{dl}$ as compared to the reference range for healthy cattle $36.35 \pm 1.52$ (Pal \& Acharya, 2013). Hypoglycemia may be due to large amount of blood glucose withdrawal by the mammary gland for the synthesis of milk lactose (Hagawane et al., 2009). As highest dry matte intake doesn't occur until 8-10 weeks after calving but peak milk production is at 4-6 week and energy intake may not keep up with demand (Kahn et al., 2010). These cows are more prone to ketosis due to lipolysis of fat to fulfill the negative energy balance. Rest of the serum biochemical parameters tested was found within the referential range.

\section{CONCLUSION}

The values which are in normal range can be used as reference values at lactating stage of cross-bred Jersey cattle for similar climate and season. The variables significantly different are not recommended as baseline value. Further detail studies are needed to exacting the standard reference value for this breed of cattle especially regarding the serum biochemical parameters which will be helpful to uncover the subclinical metabolic diseases.

\section{ACKNOWLEDGEMENT}

This research was supported by Institute of Agriculture and Animal Science, Rampur, Chitwan and Regional Veterinary Disease Diagnostic Laboratory, Ramghat, Pokhara. The author would like to thank Dr. Prerana Sedain Bhattarai for the encouragement and motivation during the study period. The authors also wish to express sincere thanks to all the staff of Regional Veterinary Disease Diagnostic Laboratory, Ramghat, Pokhara for their cooperation.

\section{REFERENCES CITED}

Ametaj, B.N. (2014). Metabolic disorders of dairy cattle. Encyclopedia of Life Support Systems (EOLSS): Veterinary Science. Developed under the Auspices of the UNESCO, Eolss Publishers; Paris, France: 2014

Benjamin, M. M. (1986). Outline of veterinary clinical Pathology, 3rd Edition, The Iwoa State Uni. press, Ames, Iwoa, USA: 7-8, 29-30.

Bozdogan, O., \& Baysal A.I. (2003). The Effect of Age, Sex, Housing System and Pregnancy on Some Blood Parameters of Tuj Sheep. Turk J Vet Anim Sci, 27, 521-524.

Cozzi, G., Ravarotto, L., Gottardo, F., Stefani, A. L., Contiero, B., Moro, L., \& Dalvit, P. (2011). Short communication: Reference values for blood parameters in Holstein dairy cows: Effects of parity, stage of lactation, and season of production. Journal of Dairy Science (Vol. 94). https://doi.org/10.3168/jds.2010-3687

Hagawane, S. D., Shinde, S. B., \& Rajguru, D. N. (2009). Haematological and Blood Biochemical Profile in Lactating Buffaloes in and around Parbhani city. Veterinary World, 2(12).

Jain, N. C., \& Lasmanis, J. (1978). Leucocytic changes in cows given intravenous injections of Escherichia coli endotoxin. Research in Veterinary Science, 24(3), 386-7.

Kahn, C. M., Line, S., \& Merck \& Co. (2010). The Merck veterinary manual. Merck \& Co.

Kongara, K. (2008). Studies on renal safety and preventive analgesic efficacy of tramadol and parecoxib in dogs : thesis in fulfilment of the degree of Doctor of Philosophy in Veterinary Clinical Science, Institute of Veterinary Animal and Biomedical Sciences, College of Sciences, Massey University, Palmerston North, New Zealand. 
Lee, A. J., Twardock, A. R., Bubar, R. H., Hall, J. E., Davis, C. L., \& Prouiz, J. (1978). Blood metabolic profiles: their use and relation to nutritional status of dairy cows. Journal of Dairy Science, 61(11), 1652-70. https://doi.org/10.3168/jds.S0022-0302(78)83780-1

Mahima, Singh, K. V., Verma, A. K., Kumar, V., Singh, S. K., \& Roy, D. (2013). Hematological and serum biochemical profile of apparently healthy hariana cattle heifers in Northern India. Pakistan Journal of Biological Sciences. https://doi.org/10.3923/pjbs.2013.1423.1425

McCullough, M. (1969). Optimum feeding of dairy animals. University of Georgia Press, Athens, GA.

Nehra, P. (2016). Blood biochemical parameters in response to lactation stress in Sahiwal cattle. Rajasthan University of Veterinary and Animal Sciences, Bikaner - 334001.

Pal, P., \& Acharya, H. R. (2013). Subclinical metabolic disorders in post-partum cross bred HF cattle. International Journal of Pharma Medicine and Biological Sciences, 2(2), 57-62.

Pal, P., \& Bhatta, R. (2013)." Determination of Blood Metabolites in Cross HF Cattle at Pre-Parturient Stage: Reference Value".International Journal of Pharma Medicine and Biological Sciences, 2(1), 53-57. Retrieved June 7, 2017, from http://www.ijpmbs.com/index.php?m=content\&c=i ndex \&a $=$ show \&catid $=115 \&$ id $=43$

Pathan, M. M., Das, H., Md. J. Z, Siddiquee, G. M., Latif, A., Parsani, H. R., Sastry, G. A. (2011). Comp arative studies on haemato-biochemical profile of cyclic and non-cyclic Holstein Friesian cross-bred cows. Wayamba Journal of Animal Science. pp.69-70

Radostits, O. M., \& Done, S. H. (2007). Veterinary medicine : A textbook of the diseases of cattle, sheep, pigs, goats, and horses. Elsevier Saunders. 